\title{
Coronaphobia in patients with fibromyalgia
}

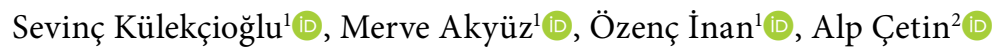 \\ ${ }^{1}$ Department of Physical Therapy and Rehabilitation, Bursa City Hospital, Bursa, Türkiye \\ ${ }^{2}$ Department of Physical Medicine and Rehabilitation, Medicine Faculty of Hacettepe University, Ankara, Türkiye
}

\begin{abstract}
Objectives: This study aims to evaluate the level of coronaphobia caused by the novel coronavirus disease 2019 (COVID-19) pandemic in patients with fibromyalgia syndrome (FMS) and to compare the results in patients without FMS.

Patients and methods: Between August 2020 and October 2020, a total of 61 patients who were admitted to our outpatient clinic were included. The patients were divided into two groups as Group 1 ( $n=30 ; 2$ males, 28 females; mean age: $43.2 \pm 9.3$ years; range, 21 to 61 years) consisting of patients who were newly diagnosed or under follow-up for FMS and Group 2, the control group, ( $n=31 ; 4$ males, 27 females; mean age: $49 \pm 10.7$ years; range, 25 to 66 years) consisting patients who presented with any locomotor system complaint and were not diagnosed with FMS. Sociodemographic data of the patients and comorbidities were recorded. All the patients in both groups completed the COVID-19 Phobia Scale (C19P-S).

Results: The C19P-S total score and psychological, psychosomatic, social, and economic subscale scores were statistically significantly higher in the FMS group than the control group $(p<0.05)$.

Conclusion: Our study results suggest that FMS patients have more concerns in this extraordinary global pandemic situation. Early detection of coronaphobia and timely psychological support are critical for individuals prone to psychological disorders, such as FMS.

Keywords: Coronaphobia, COVID-19, fibromyalgia, pandemic, specific phobia.
\end{abstract}

The novel coronavirus disease 2019 (COVID-19), started in Wuhan, China in December 2019 and spread rapidly across the world, was declared a global pandemic on March $11^{\text {th }}$, 2020 by the World Health Organization (WHO). ${ }^{1}$ Throughout the world, the COVID-19 pandemic has a significant effect on human health and daily life. Long-term social isolation, quarantine, fear of the disease, financial problems, and uncertainty about the future have led to negative psychosocial and economic impacts stresses, beyond physical diseases. Constant exposure to news of COVID-19 in print, visual, and social media with the continuing increase in COVID-19 deaths and the fact that the virus is still not under control has increased the level of concern and fear among individuals. ${ }^{2}$

It is well known that such outbreaks can cause different psychological difficulties including fear and panic in society. Fear and anxiety disorders have been reported to have increased in previous similar pandemics such as $\mathrm{H} 1 \mathrm{~N} 1$, severe acute respiratory syndrome (SARS), Middle East respiratory syndrome (MERS), Ebola, and Zika. ${ }^{3-5}$ There are recent data in the literature showing that the COVID-19 pandemic has increased mental health problems such as anxiety disorders, depression, and acute stress disorder. ${ }^{6-9}$ Phobias are specific anxiety disorders defined as an

Received: December 24, 2020 Accepted: August 07, 2021 Published online: October 10, 2021

Correspondence: Sevinç Külekçioğlu, MD. Bursa Şehir Hastanesi Fizik Tedavi ve Rehabilitasyon Kliniği, 16110 Nilüfer, Bursa, Türkiye. Tel: +90 532 - 3157737 e-mail: sevinckulek@gmail.com

\section{Citation:}

Külekçioğlu S, Akyüz M, İnan Ö, Çetin A. Coronaphobia in patients with fibromyalgia. Arch Rheumatol 2022;37(2):180-186. 
excessive and continuous fear of an object or situation. ${ }^{10,11}$ Coronaphobia is defined as a specific phobia of the new coronavirus in the COVID-19 pandemic, and a scale, the COVID-19 Phobia Scale (C19P-S), has been developed to measure this specific phobia. ${ }^{12}$

Fibromyalgia syndrome (FMS) is a chronic disease characterized by symptoms such as widespread musculoskeletal system pain, fatigue, sleep disorder, cognitive problems, depression, and anxiety. ${ }^{13}$ It is one of the most frequent musculoskeletal system disorders, which is seen more often in females than males with an estimated prevalence of 2 to $4 \%$ in the general population. ${ }^{14}$ In general, FMS patients may have accompanying anxiety, anxiety disorders, and depression at varying degrees between 20 and $80 \% .{ }^{13}$ Furthermore, the emergence of new challenges in accessing treatment due to the COVID-19 pandemic can increase pre-existing anxiety for individuals struggling with chronic pain.

In the present study, we aimed to evaluate the level of coronaphobia caused by the COVID-19 pandemic in FMS patients and to compare the results in patients without FMS.

\section{PATIENTS AND METHODS}

This single center, cross-sectional, controlled study was conducted at Bursa City Hospital, Department of Physical Medicine and Rehabilitation between August 2020 and
October 2020. A total of 61 patients who were admitted to our outpatient clinic were included. The patients were divided into two groups as Group 1 ( $\mathrm{n}=30$; 2 males, 28 females; mean age: $43.2 \pm 9.3$ years; range, 21 to 61 years) consisting of patients who were newly diagnosed or under follow-up for FMS according to the 2016 American College of Rheumatology (ACR) criteria and Group 2, the control group, $(n=31$; 4 males, 27 females; mean age: $49 \pm 10.7$ years; range, 25 to 66 years) consisting patients who presented with any locomotor system complaint and were not diagnosed with FMS. All patients included were aged $>18$ years and completed at least five years of compulsory primary education. Patients were excluded from the study, if they had any severe systemic disease, a malignancy, acute infection, pregnancy, or breastfeeding, or if they had a history of psychiatric or neurological disease.

Sociodemographic data (age, sex, height, weight, education, occupation, and marital status) of all the patients and comorbidities were recorded. All patients in both groups were asked to complete the CP19-S to measure their level of fear related to COVID-19. The items of the scale were formed on the basis of an extensive review of existing scales of fear, specialist evaluations, and the opinions of participants. The validity and reliability of the CP19-S for a Turkish population was examined, and the scale items were seen to have high differentiation and high reliability values. ${ }^{15}$ The scale is evaluated with a five-point Likert type scale where 1 indicates "Completely disagree" and 5 indicates "Completely agree".

Table 1. Demographic data of participants

\begin{tabular}{|c|c|c|c|c|c|c|c|}
\hline & \multicolumn{3}{|c|}{ FMS group $(n=30)$} & \multicolumn{3}{|c|}{ Control group $(\mathrm{n}=31)$} & \multirow[b]{2}{*}{$p^{*}$} \\
\hline & $\mathrm{n}$ & $\%$ & Mean \pm SD & $\mathrm{n}$ & $\%$ & Mean \pm SD & \\
\hline Age (year) & & & $43.2 \pm 9.3$ & & & $49 \pm 10.7$ & 0.082 \\
\hline Sex & & & & & & & 0.417 \\
\hline Female & 28 & 93.3 & & 27 & 87.1 & & \\
\hline Male & 2 & 6.7 & & 4 & 12.9 & & \\
\hline Height $(\mathrm{cm})$ & & & $162 \pm 3.4$ & & & $164.9 \pm 7.3$ & 0.137 \\
\hline Weight (kg) & & & $71.1 \pm 13.5$ & & & $71.1 \pm 13.8$ & 0.874 \\
\hline Marital status & & & & & & & 0.180 \\
\hline Married & 22 & 73.3 & & 27 & 87.1 & & \\
\hline Single & 8 & 26.7 & & 4 & 12.9 & & \\
\hline
\end{tabular}


The scale is evaluated in psychosomatic, social, and economic subscales. The total scale points, ranging from 20 to 100 , are obtained as the

Table 2. Professions of participants

\begin{tabular}{lccccc}
\hline & \multicolumn{2}{c}{ FMS group } & & \multicolumn{2}{c}{ Control group } \\
\cline { 2 - 3 } \cline { 5 - 6 } Professions & $\mathrm{n}$ & $\%$ & & $\mathrm{n}$ & $\%$ \\
\hline Housewife & 16 & 53.3 & & 15 & 48.4 \\
Student & - & - & & 1 & 3.2 \\
Worker & 6 & 20 & & 5 & 16.1 \\
Retired & 2 & 6.7 & & 4 & 12.9 \\
Secretary & - & - & & 1 & 3.2 \\
Operator & - & - & & 3 & 9.7 \\
Sales consultant & - & - & & 2 & 6.4 \\
Technician & 1 & 3.3 & & - \\
Farmer & 1 & 3.3 & & - & - \\
Accountant & 1 & 3.3 & & - \\
Security guard & 1 & 3.3 & & - \\
Teacher & 1 & 3.3 & & - \\
Nurse & 1 & 3.3 & & - \\
Total & 30 & 100 & & 31 & 100 \\
\hline FMS: Fibromyalgia syndrome. & & & & \\
\cline { 5 - 6 } & & & & &
\end{tabular}

Table 3. Education status of participants

\begin{tabular}{lccccc}
\hline & \multicolumn{2}{c}{ FMS group } & & \multicolumn{2}{c}{ Control group } \\
\cline { 2 - 3 } \cline { 5 - 6 } Education status & $\mathrm{n}$ & $\%$ & & $\mathrm{n}$ & $\%$ \\
\hline Primary school & 15 & 50 & & 12 & 38.7 \\
High school & 11 & 36.7 & & 11 & 35.5 \\
Bachelor's degree & 4 & 13.4 & & 8 & 25.8 \\
Total & 30 & 100 & & 31 & 100 \\
\hline FMS: Fibromyalgia syndrome. & & & &
\end{tabular}

Table 4. Comparison of C19P-S Scores of participants

\begin{tabular}{|c|c|c|c|}
\hline & $\begin{array}{l}\text { FMS group } \\
(\mathrm{n}=30)\end{array}$ & $\begin{array}{l}\text { Control group } \\
\quad(n=31)\end{array}$ & \\
\hline C19P-S Score $†$ & Mean \pm SD & Mean \pm SD & $p^{*}$ \\
\hline Psychological & $23.2 \pm 5.0$ & $16.3 \pm 6.5$ & $<0.001$ \\
\hline Psychosomatic & $10.9 \pm 4.4$ & $7.1 \pm 2.9$ & $<0.001$ \\
\hline Social & $18.4 \pm 4.5$ & $12.1 \pm 5.4$ & $<0.001$ \\
\hline Economic & $10.5 \pm 3.3$ & $6.5 \pm 3.4$ & $<0.001$ \\
\hline Total & $63.3 \pm 12.7$ & $41.7 \pm 15.9$ & $<0.001$ \\
\hline
\end{tabular}

total of the subscale points, with higher scores indicating a greater level of fear of COVID-19.

\section{Statistical analysis}

Statistical analysis was performed using the IBM SPSS version 20.0 software (IBM Corp., Armonk, NY, USA). Descriptive data were expressed in mean \pm standard deviation (SD), median (min-max) or number and frequency. For the comparison of the C19P-S results between the groups, the independent samples t-test was used. The Mann-Whitney U test was used to compare the differences between two independent groups. A $p$ value of $<0.05$ was considered statistically significant.

\section{RESULTS}

Demographic characteristics of the patients are shown in Table 1 . There was no significant difference between the FMS patients and the control group in terms of age, sex, height, weight, and marital status ( $p>0.05)$.

Professions and educational status of the study group are given in Table 2 and 3 . Accordingly, $53.3 \%$ and $48.4 \%$ of the FMS and control groups were housewives, respectively. In addition, $50 \%$ and $38.7 \%$ of the FMS and control groups completed five-year primary school education, respectively. Four (13.4\%) patients in the FMS group and eight (25.8\%) patients in the control group had a bachelor degree.

The results of the C19P-S are shown in Table 4. Accordingly, the C19P-S total score and psychological, psychosomatic, social, and economic subscale scores were statistically significantly higher in the FMS group than the control group $(p<0.001)$.

\section{DISCUSSION}

In the present study, we compared the level of coronaphobia caused by the COVID-19 pandemic in patients with and without FMS. The study results showed that coronaphobia was statistically significantly more common among the FMS patients than the control group. To the best of our knowledge, the present study 
is the first to examine coronaphobia in FMS patients.

In the literature, the association of FMS with anxiety disorders has been well documented. Previous studies have shown that FMS patients are affected more than healthy individuals by concerns and anxiety triggered by stress factors. ${ }^{16}$ Several studies have demonstrated that the majority of patients with FMS have various psychosocial problems and psychiatric disorders including depression, anxiety, somatization, and phobias. ${ }^{13,14,16-18}$ About 19.4 to $34.8 \%$ of FMS patients have emotional disorders, and 11.6 to $32.2 \%$ of them have anxiety and anxiety disorders. ${ }^{13,14}$ Uğuz et al. ${ }^{18}$ reported that specific phobias were seen more frequently in FMS patients, although there are insufficient data investigating specific phobia types in FMS. In addition to the physical threat and destruction, COVID-19 leads to stress reaction and trauma caused by what has been experienced related to the disease. ${ }^{19}$ Besides to environmental conditions, specific phobias may emerge associated with the existing psychological status, diseases, temperament, genetic, and physiological precursors. ${ }^{10}$ It is thought that the psychological status, temperament, and personal characteristics of FMS patients facilitate the development of specific phobias. ${ }^{20-23}$ The difficulties experienced by FMS patients due to the COVID-19 pandemic in many activities, exercise, and accessing regular medical treatment are considered to increase anxiety and phobic reactions. In a study by Haktanir et al. ${ }^{24}$ there was no significant difference between patients with and without chronic disease in respect of fear of COVID-19. In this study, the Fear of COVID-19 Scale was used in the evaluation of the fear of COVID-19; however, the patients previously diagnosed with anxiety were excluded from the study. Therefore, it cannot be suggested that these results represent the general population. In the current study, however, we demonstrated that the presence of FMS as a chronic disease increased the risk of coronaphobia.

It has been reported from several countries that the COVID-19 pandemic has significant negative psychological, social, and economic impacts. The negative psychological effects of COVID-19 started to be investigated first in China where the pandemic first emerged and, then, in countries such as Italy and Spain where severe effects of the pandemic were seen. ${ }^{25-27}$ In a study including 7,143 university students in China after the COVID-19 outbreak, symptoms of anxiety were experienced at an intense level in $0.9 \%$, at a moderate level, in $2.7 \%$, and at a mild level in $21.3 \%$ of the students. ${ }^{25}$ Similarly in another study in China of 1,210 individuals, the psychological effects of the pandemic were examined, and $16.5 \%$ of the participants showed symptoms of depression from a moderate-to-severe level, $28.8 \%$ had moderateto-severe anxiety symptoms, and $8.1 \%$ showed moderate-to-severe stress symptoms. ${ }^{28} \mathrm{~A}$ study of 3,550 adults conducted over the internet in Spain revealed anxiety disorder in 32.4\%, depression in $44.1 \%$, and stress disorder in $37 \%$ of the respondents. ${ }^{29}$ To examine the effect of the pandemic and quarantine period on psychological health, Rossi et al., ${ }^{27}$ conducted an online questionnaire with 18,147 respondents in Italy and reported that post-traumatic stress symptoms were seen in $37 \%$, anxiety symptoms in $20.8 \%$, depression symptoms in $17.3 \%$, sleep problems in $7.3 \%$, and perceived high levels of stress in $21.8 \% .{ }^{27}$ In the current study, a significant difference was found in the psychological and psychosomatic phobia subscales among the FMS patients. Anxiety and fear caused by the nature of the pandemic can also affect interpersonal relationships in daily life. To illustrate, more than half of individuals who were quarantined with the suspicion that they were in contact with a SARS-infected person reported that, weeks later, they attempted to self-isolate themselves from anybody who sneezed or coughed, 26\% stayed away from crowded or indoor places, and $21 \%$ avoided all areas open to the public. ${ }^{30,31}$ In the current study, the social phobia variables were found to be high in the FMS patient group. The economic variables in the current study were also found to be higher in the FMS patients due to many reasons such as having to continue with existing work, not going to work due to social isolation, being made redundant, and difficulties in finding a new job.

For the evaluation of specific phobias, it is recommended to use evaluation questionnaires specific to that fear. Thus, a need has arisen for the evaluation of the fear of COVID-19, and 
different scales have been developed for this purpose. $^{32}$ In the current study, the C19P-S questionnaire was used, which was originally developed to evaluate coronaphobia. The C19P-S was previously tested for validity and reliability in the Turkish population. ${ }^{15} \mathrm{~A}$ previous review showed that the C19P-S was one of the few scales to comprehensively evaluate mental health problems related to COVID-19. ${ }^{33}$ In a study by Toprak Celenay et al. ${ }^{34}$ using the C19P-S, the levels of coronaphobia were compared in individuals who stayed at home during the pandemic and those who continued to work. However, apart from those with severe psychological problems, other health problems were not taken into consideration in this study. It is possible that the presence of additional diseases has an effect on coronaphobia. A substantial amount of evidence has shown that the COVID-19 pandemic has deep psychological and social effects. The psychological sequelae of the pandemic would probably continue for months and years in the future. ${ }^{35}$ Therefore, in this extraordinary situation in which we find ourselves, it is of utmost importance to identify individuals with a predisposition to psychological disorders from different groups, and with the implementation of appropriate psychological strategies, techniques and interventions, the mental health of the general population can be protected and improved. ${ }^{36}$ Identification of COVID-19 phobia and the provision of timely psychological support are also critical. ${ }^{37}$

The main limitations of this study are its cross-sectional design and small sample size. Therefore, it is not possible to provide information about why coronaphobia is seen more often in FMS patients or what causes the development of coronaphobia in FMS. Further large-scale, long-term, prospective studies are needed to gain a better understanding of the cause-and-effect relationships.

In conclusion, our study results suggest that FMS patients have more concerns in this extraordinary global pandemic situation. Early detection of COVID-19 phobia and providing timely psychological support are important in individuals prone to psychological disorders such as FMS. We believe that this study is valuable as it provides contribution to the literature regarding the presence of coronaphobia in FMS patients.

Ethics Committee Approval: The study protocol was approved by the Bursa City Hospital Clinical Research Ethics Committee (Date-no: 2019-KAEK-140). The study was conducted in accordance with the principles of the Helsinki Declaration.

Patient Consent for Publication: All patients were informed about the nature of the study and a written informed consent was obtained on a voluntary basis.

Data Sharing Statement: The data that support the findings of this study are available from the corresponding author upon reasonable request.

Author Contributions: Design, data collection and processing, analysis and interpretation, writing: S.K.; Data collection and processing, analysis and interpretation, writing: M.A.; Data collection and processing: Ö.İ.; Idea, concept, concultancy, analysis and interpretation: A.Ç. All authors read and approved the final manuscript.

Conflict of Interest: The authors declared no conflicts of interest with respect to the authorship and/or publication of this article.

Funding: The authors received no financial support for the research and/or authorship of this article.

\section{REFERENCES}

1. World Health Organization. World health report 2020: Coronavirus disease (COVID-19) pandemic. Available at: https://www.euro.who.int/en/healthtopics/healthemergencies/coronavirus-covid-19/ novel-coronavirus-2019-ncov.

2. Asmundson GJG, Taylor S. Coronaphobia: Fear and the 2019-nCoV outbreak. J Anxiety Disord 2020;70:102196.

3. Ibrahim NK. Zika virus: Epidemiology, current phobia and preparedness for upcoming mass gatherings, with examples from World Olympics and Pilgrimage. Pak J Med Sci 2016;32:1038-43.

4. Kim CW, Song HR. Structural relationships among public's risk characteristics, trust, risk perception and preventive behavioral intention: The case of MERS in Korea. Crisis and Emergency Management 2017;13:85-95.

5. Liu ZG, Zhang KR, Lu ZX. Follow-up study on phobia emotion of SARS patients. Journal of Shanxi Medical University 2005;1:62-4.

6. Hu W, Su L, Qiao J, Zhu J, Zhu Y. COVID-19 outbreak increased risk of schizophrenia in aged adults. Clinical TMS Society 2020;3:1-18.

7. Huang C, Wang Y, Li X, Ren L, Zhao J, Hu Y, et al. Clinical features of patients infected with 2019 novel coronavirus in Wuhan, China. Lancet 2020;395:497-506. 
8. Huang L, Lei W, Xu F, Liu H, Yu L. Emotional responses and coping strategies in nurses and nursing students during Covid-19 outbreak: A comparative study. PLoS One 2020;15:e0237303.

9. Dai Y, Hu G, Xiong H, Qiu H, Yuan X. Psychological impact of the coronavirus disease 2019 (COVID19) outbreak on healthcare workers in China. MedRxiv 2020. Available at: https://www.medrxiv. org/content/10.1101/2020.03.03.20030874v1. full.pdf

10. Bandelow B, Michaelis S. Epidemiology of anxiety disorders in the 21st century. Dialogues Clin Neurosci 2015;17:327-35.

11. Arpaci I, Karataş K, Baloğlu M. The development and initial tests for the psychometric properties of the COVID-19 Phobia Scale (C19P-S). Pers Individ Dif 2020;164:110108.

12. Wardenaar KJ, Lim CCW, Al-Hamzawi AO, Alonso $\mathrm{J}$, Andrade LH, Benjet $\mathrm{C}$, et al. The cross-national epidemiology of specific phobia in the World Mental Health Surveys. Psychol Med 2017;47:1744-60.

13. Galvez-Sánchez CM, Montoro CI, Duschek S, Reyes Del Paso GA. Depression and trait-anxiety mediate the influence of clinical pain on healthrelated quality of life in fibromyalgia. J Affect Disord 2020;265:486-95.

14. Martínez MP, Sánchez AI, Miró E, Lami MJ, Prados G, Morales A. Relationships between physical symptoms, emotional distress, and pain appraisal in fibromyalgia: The moderator effect of alexithymia. J Psychol 2015;149:115-40.

15. Satici B, Gocet-Tekin E, Deniz ME, Satici SA. Adaptation of the fear of COVID-19 scale: Its association with psychological distress and life satisfaction in Turkey. Int $\mathrm{J}$ Ment Health Addict 2020:1-9.

16. Gündüz N, Üşen A, Aydin Atar E. The impact of perceived social support on anxiety, depression and severity of pain and burnout among Turkish females with fibromyalgia. Arch Rheumatol 2018;34:186-95.

17. Kurtze N, Gundersen KT, Svebak S. The role of anxiety and depression in fatigue and patterns of pain among subgroups of fibromyalgia patients. $\mathrm{Br} \mathrm{J}$ Med Psychol 1998;71:185-94.

18. Uguz F, Ciçek E, Salli A, Karahan AY, Albayrak I, Kaya N, et al. Axis I and Axis II psychiatric disorders in patients with fibromyalgia. Gen Hosp Psychiatry 2010;32:105-7.

19. Ho CS, Chee CY, Ho RC. Mental health strategies to combat the psychological impact of coronavirus disease 2019 (COVID-19) beyond paranoia and panic. Ann Acad Med Singap 2020;49:155-60.

20. Li W, Yang Y, Liu ZH, Zhao YJ, Zhang Q, Zhang L, et al. Progression of mental health services during the COVID-19 outbreak in China. Int $\mathrm{J}$ Biol Sci 2020;16:1732-8.
21. Duan L, Zhu G. Psychological interventions for people affected by the COVID-19 epidemic. Lancet Psychiatry 2020;7:300-2.

22. Wang C, Cheng Z, Yue XG, McAleer M. Risk management of COVID-19 by universities in China. J Risk Financial Manag 2020;13:36.

23. Xiao C. A novel approach of consultation on 2019 novel coronavirus (COVID-19)-related psychological and mental problems: Structured letter therapy. Psychiatry Investig 2020;17:175-6.

24. Haktanir A, Seki T, Dilmaç B. Adaptation and evaluation of Turkish version of the fear of COVID-19 Scale. Death Stud 2020:1-9.

25. Cao W, Fang Z, Hou G, Han M, Xu X, Dong J, et al. The psychological impact of the COVID-19 epidemic on college students in China. Psychiatry Res 2020;287:112934.

26. Odriozola-González P, Planchuelo-Gómez Á, Irurtia MJ, de Luis-García R. Psychological effects of the COVID-19 outbreak and lockdown among students and workers of a Spanish university. Psychiatry Res 2020;290:113108.

27. Rossi A, Panzeri A, Pietrabissa G, Manzoni GM, Castelnuovo G, Mannarini S. The anxiety-buffer hypothesis in the time of COVID-19: When selfesteem protects from the impact of loneliness and fear on anxiety and depression. Front Psychol 2020;11:2177.

28. Wang C, Pan R, Wan X, Tan Y, Xu L, Ho CS, et al. Immediate psychological responses and associated factors during the initial stage of the 2019 coronavirus disease (COVID-19) epidemic among the general population in China. Int $J$ Environ Res Public Health 2020;17:1729.

29. Odriozola-González P, Planchuelo-Gómez Á, Irurtia MJ, de Luis-García R. Psychological symptoms of the outbreak of the COVID-19 confinement in Spain. J Health Psychol 2020:1359105320967086.

30. Cava MA, Fay KE, Beanlands HJ, McCay EA, Wignall $\mathrm{R}$. The experience of quarantine for individuals affected by SARS in Toronto. Public Health Nurs 2005;22:398-406.

31. Reynolds DL, Garay JR, Deamond SL, Moran MK, Gold W, Styra R. Understanding, compliance and psychological impact of the SARS quarantine experience. Epidemiol Infect 2008;136:997-1007.

32. Ahorsu DK, Lin CY, Imani V, Saffari M, Griffiths MD, Pakpour AH. The fear of COVID-19 scale: Development and initial validation. Int $\mathrm{J}$ Ment Health Addict 2020:1-9.

33. Chandu VC, Marella Y, Panga GS, Pachava S, Vadapalli V. Measuring the impact of COVID-19 on mental health: A scoping review of the existing scales. Indian J Psychol Med 2020;42:421-7.

34. Toprak Celenay S, Karaaslan Y, Mete O, Ozer Kaya D. Coronaphobia, musculoskeletal pain, and sleep quality in stay-at home and continued-working 
persons during the 3-month Covid-19 pandemic lockdown in Turkey. Chronobiol Int 2020;37:177885.

35. Sher L. The impact of the COVID-19 pandemic on suicide rates. QJM 2020;113:707-12.

36. Salari N, Hosseinian-Far A, Jalali R, Vaisi-Raygani A, Rasoulpoor S, Mohammadi M, et al. Prevalence of stress, anxiety, depression among the general population during the COVID-19 pandemic: A systematic review and meta-analysis. Global Health 2020;16:57.

37. Qiu J, Shen B, Zhao M, Wang Z, Xie B, Xu Y. A nationwide survey of psychological distress among Chinese people in the COVID-19 epidemic: Implications and policy recommendations. Gen Psychiatr 2020;33:e100213. 